\title{
Case Study for Road Safety Audit of Aurangabad City
}

\author{
Prashant Awsarmal ${ }^{*}$, S. L. Hake ${ }^{2}$, Shubham Vaidya ${ }^{1}$ P. K. Bhandari ${ }^{2}$, M. P. Wagh ${ }^{2}$ \\ ${ }^{1}$ Department of Civil Engg., G.S. Mandal's Maharashtra Institute of Technology, Aurangabad, M.H., India \\ ${ }^{2}$ Department of Civil Engg., Dr.V.V.P. College of Engineering, Ahmednagar, M.H., India
}

\begin{abstract}
Efficient road network is a part-n-parcel of rapid industralization, urbanization and development of nation. While designing roads and highways, main emphasis is given on speed which will help to reduce time of journey and save fuel. But safety of drivers and passengers travelling along road is also important. In past, it was observed that while travelling, due to excess speed passengers safety was compromised. It will lead to accidents. It may cause severe injuries and loss of human life. Therefore it is important to check every aspect of vehicles as well as road during its design, construction and throughout the life of the road. Road safety audit is conducted to check performance of new road projects on grounds of offering maximum safety. Also checks are applied to study performance of existing roads to suggest repairs, rehabiliatation and maintenance work in order to improve condition of roads. During audit process, accident prone locations are identified. Past accident record from traffic department, Police department, hospitals etc are referred to understand damage that had occured. Even road geometry is investigated on technical basis. In present investigation, particular stretch of Beed Bypass Road passing through Aurangabad city in Maharashtra state, India was selected. On this road, accident sites where major accidents occurred in past were identified and investigated for different parameters. Based upon study, different causes of accidents and thereafter preventive methods were recommended during research work.
\end{abstract}

\section{Introduction}

\subsection{Background}

Planning and geometric design of road network has found place way back in history. In past, it was seen that during wars, roads were used for fast and strategic movement of army troops. Even for civilian use, roads are lifeline for development of nation. It is necessary to ensure that these roads are kept in working condition and should be safe for passengers to travel on roads. The process to ensure road safety is done through 'Road Safety Audit (RSA)'. It was first adopted in United Kingdom (UK) in 1980's. By next decade, in 1990 it was adopted in Australian continent. In America, RSA was adopted only after mid 1990's. It can be said that UK was pioneer in adapting RSA, thereafter successfully adapted in Australia and New Zealand. Austroads Guidelines were used to ensure road safety in Australia. Denmark was the country where RSA was made compulsory for all highway projects. By observing benefits achieved through RSA, World Bank has made RSA process compulsory in all road projects funded by them.

Road safety audit (RSA) includes investigating new as well as existing roads to study geometric design of roads [1]. Also find accident causes, effects and provisions made to avoid further accidents. It is believed that 'prevention is better than cure'. As per this proverb well designed road will ensure safety of people driving vehicles. RSA can be performed at any stage during lifecycle of road project $[2,3]$.

\subsection{Objective}

Since RSA is performed to ensure safety, it will also check that design of road components such as road junctions must be planned as per traffic safety guidelines. In present investigation, Beed Bypass Road passing through Aurangabad city was considered. Two road junctions, MIT chowk and Deolai chowk were selected for further investigation. The number of accidents which had occurred in past at these two black spots were studied in detail. Reasons for accident were investigated in scientific manner. Different remedial measures to avoid further accidents were also found and applied in model study to ensure its trustworthiness.

The objectives of the present study are:

1. To collect project documents of Beed Bypass road, particularly study road geometry of road. Also determine traffic intensity along this length of road.

2. Based upon data collected from traffic and police department, identify locations where maximum number of accidents occurred in past.

3. To identify defects and conflict points on the road network responsible for accidents.

\footnotetext{
*Corresponding author: drsandeephake@gmail.com
} 
4. Mark locations of accident prone areas on maps.

5. To identify safety influencing parameter in reducing accidents rate.

6. To study the traffic flow pattern, type and number of vehicles running along selected stretch of road.

7. To study the causes of accidents and suggest corrective measures at potential location.

8. Create awareness amongst road users to follow traffic rules.

\subsection{Road accident situation in India}

Fig. 1 indicates the number of accidents have decreased by considering data of previos four years. By adapting safety measures and awareness amongst drivers helped to reduce accidents.

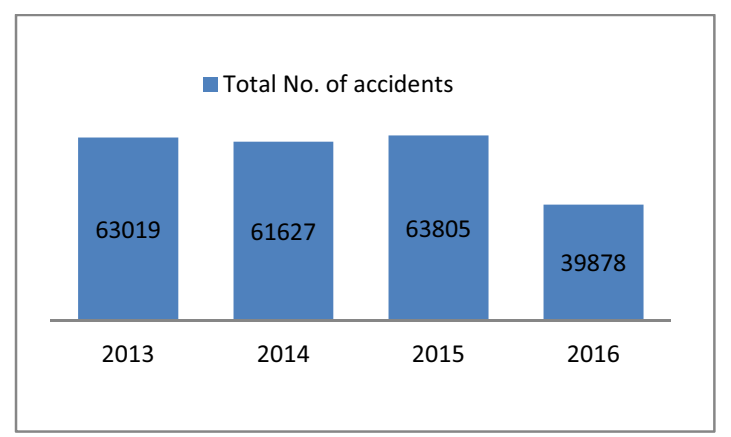

Fig. 1 Total Number of Road Accidents in India (2013-2016).

\subsection{Problem statement}

Fig. 2 shows the map of Beed bypass road passing through Aurangabad city, Maharshtra state, India. As per past data, more number of accidents occured along this road. Their was a need to investigate the reasons for accidents and thereby suggest measures to avoid accidents. By adapting Road safety audit, past accident data will be investigated and based upon analysis, factors affecting traffic pattern, accidents, drivers reaction will ne considered to propose safety measures required.

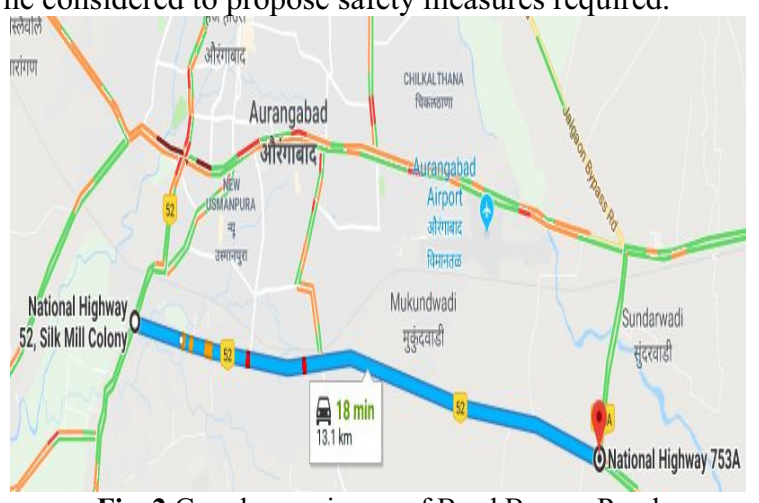

Fig. 2 Google map image of Beed Bypass Road
The scope of the study is to reduce accidents on road network, reduce severity of accidents also avoid costly remedial work. The road selected for the study is Beed Bypass road $(13.150 \mathrm{~km})$. It is stretched between two points, Mahanubhav Ashram (T- point of Paithan road) to Zalta Phata. These two road junctions MIT chowk and Deolai chowk are marked and further RSA investigation work carried at these two locations. The accident analysis will be done from previous year's data.

\section{2literature Review}

Investigation of past work has revealed several problems associated with geometry and vehicle safety. Although vehicles are designed by following all safety guidelines, but they are not able to keep people safe in event of accident. Thus, there was need to access causes of accidents and pin-point accident prone locations along the road to make retifications in road geometry.

K. Meshram and H.S. Goliya [4], performed accident analysis on NH-3 stretched between Indore to Dhamnod. Required information was collected for 3 years inbetween 2009 to 2011. Both researchers made conclusion that, pinpoint location of accident was at Manipur region owing due to errors made while constructing road. Also accident rate is more in urban region especially in Indore city. It was about $35 \%$ of total accidents that have occurred in a year. Causes of accidents were also investigated and it was revealed that tendency of drivers to drive fast and more number of vehicles running on road was the major problem behind the accidents. Most of the accidents had occurred during night time between 6 to $8 \mathrm{pm}$. Since more number of buses plying on road during night time, carrying passengers from city back to village. Number of casualties during accidents was also recorded. And as per record one fatal and five deaths are reported per $\mathrm{km}$ stretch per year along this NH-3 road.

A. Theofilatos and G. Yannis [5] studied the impact of weather on roads. Effect of rains, heavy winds, storms, fog etc can reduce the speed of traffic and may cause an accident due to reduced visibility. Relationship of traffic parameters like traffic flow with number of accident was investigated. During rainy season, due to extreme weather and poor visibility chances of accidents are more. But it was observed that if drivers are following traffic rules then it will avoid accidents. As per actual data received from road survey, it was observed that other weather conditions like fog, wind storms, temperature had no direct effect on traffic flow.

A.B. Labana et al [6] performed road survey on NH-113 running from Dahod to Jhalod to find locations where maximum accidents occurred during span of 2010 to 2014. Based upon data received it was found that 509 accidents occurred during case study period. Investigation of accident spot showed that there was no median at centreline of road which leads to head collision of vehicles coming from opposite direction. $42.63 \%$ accidents occurred during summer season in 
month of March and April. 26.62\% two wheelers and $27.5 \%$ cars were involved in accidents.

O. Gholap et al [7] has summarised reasons which were behind major accidents. As per author potholes cause health issues like back pain and even lead to fatal accidents. Information sign board and regulatory sign boards are important to give warning to drivers and make them to drive carefully with safety. All markings on roads must be painted and maintained from time to time. Thus, recommended need of regular road safety checking and maintaining audit report.

\section{Study of Black Spot}

\subsection{Accident record}

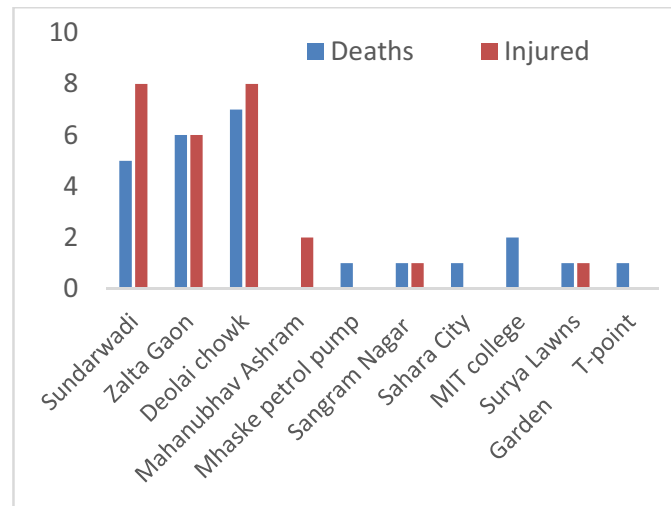

Fig. 3 Number of Injured \& deaths at accident locations.

Fig. 3 showed different location along the stretch of Beed Bypass road where number of accidents occurred, were recorded. Corresponding injured and deaths also recorded. This data was made available from past records. It was observed that maximum accidents have occurred at Sundarwadi, Zalta gaon and Deolai chowk junctions. These locations also recorded maximum number of deaths and injured people. For further investigation Deolai chowk which recorded maximum accidents and MIT chowk which was near an educational institution, which may be prone to accident was considered for next investigation.

\subsection{Observations}

Fig. 4-10 shows photographs taken during investigation at MIT chowk and Deolai chowk. Different aspects of road geometry were studied from photographs and based upon actual investigation comments were made further.

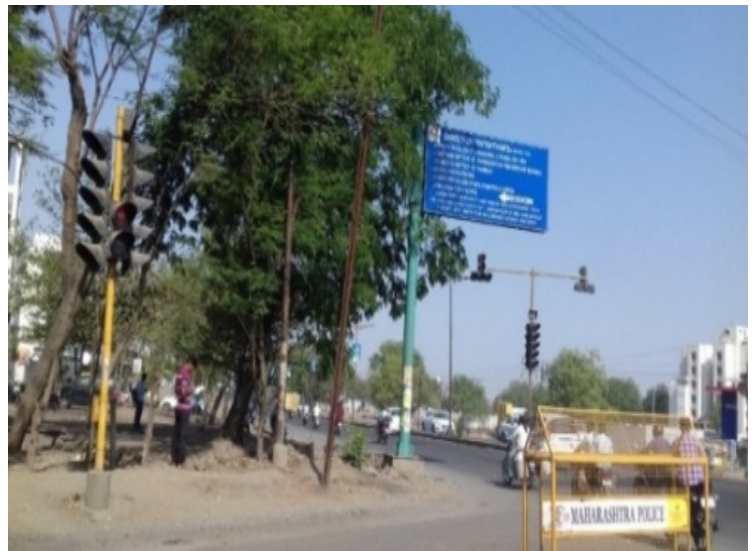

Fig. 4 Sign board post at turning obstructs vehicles
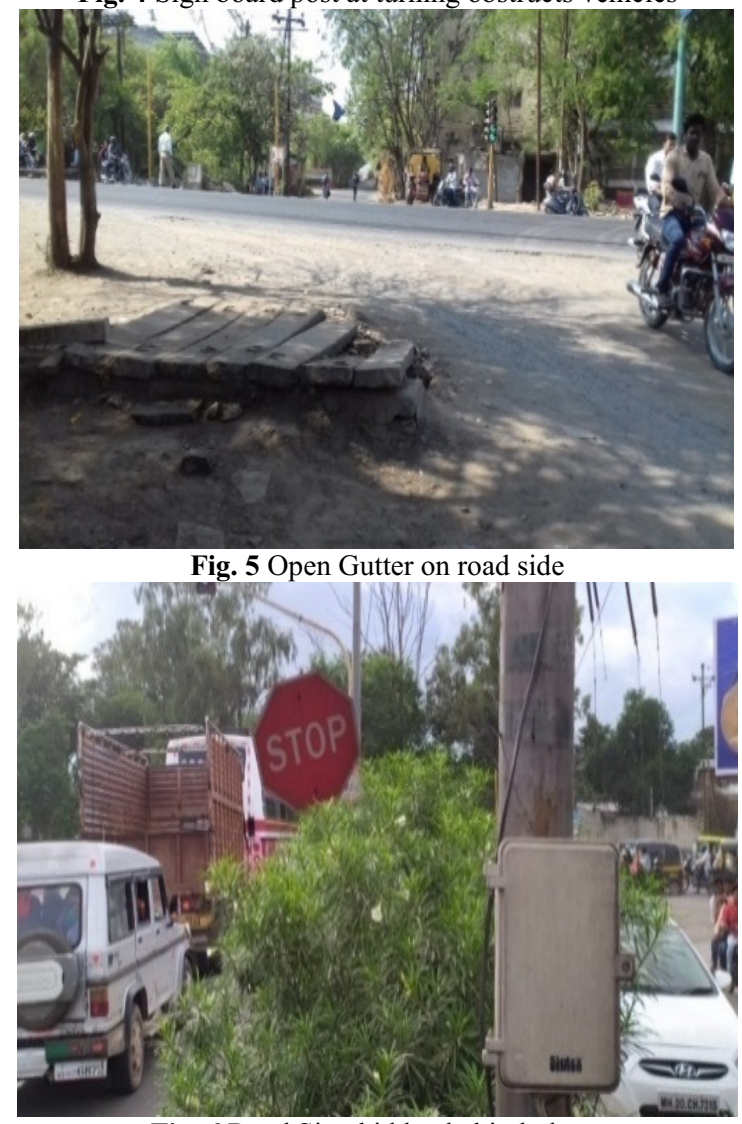

Fig. 6 Road Sign hidden behind plants

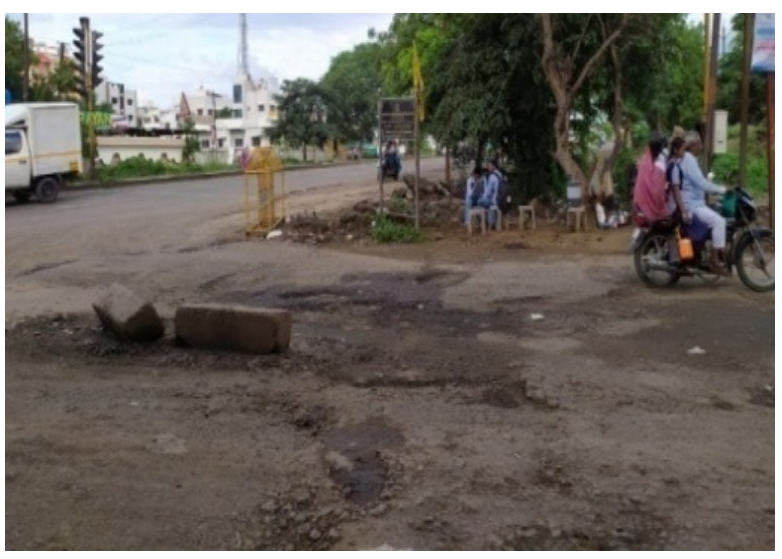

Fig. 7 Pot holes at MIT chowk 

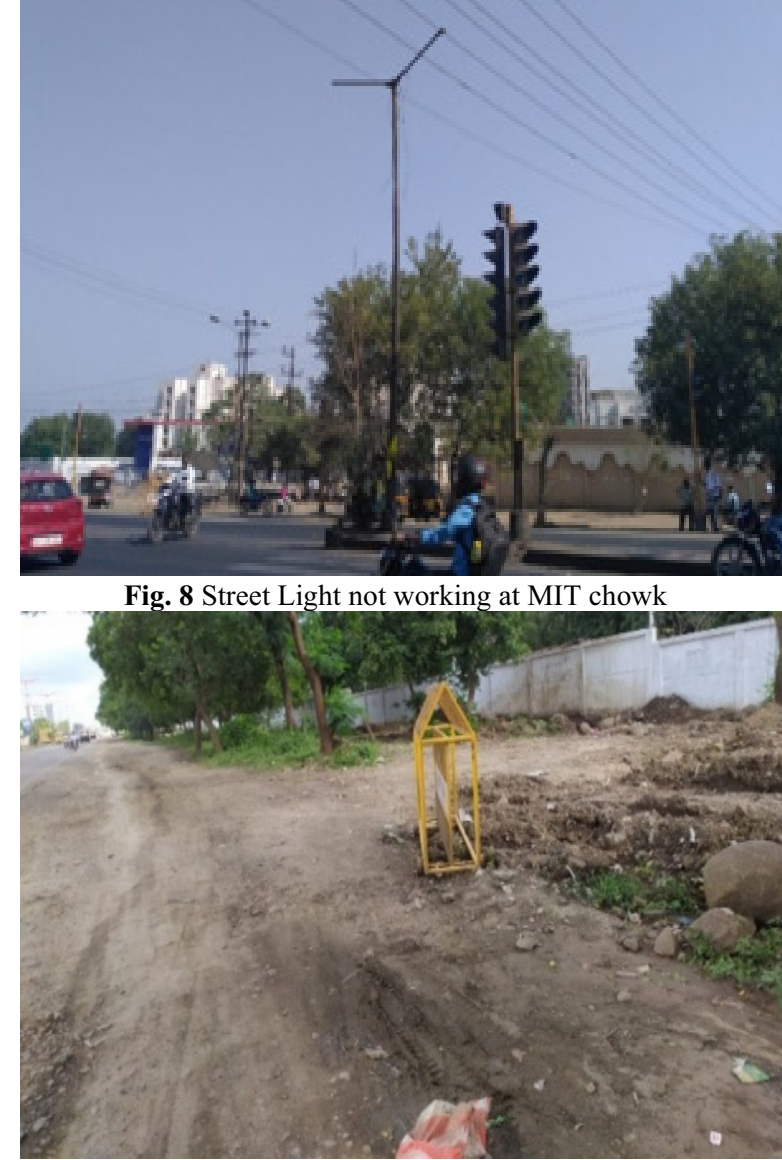

Fig. 9 Uneven Service Road at MIT chowk

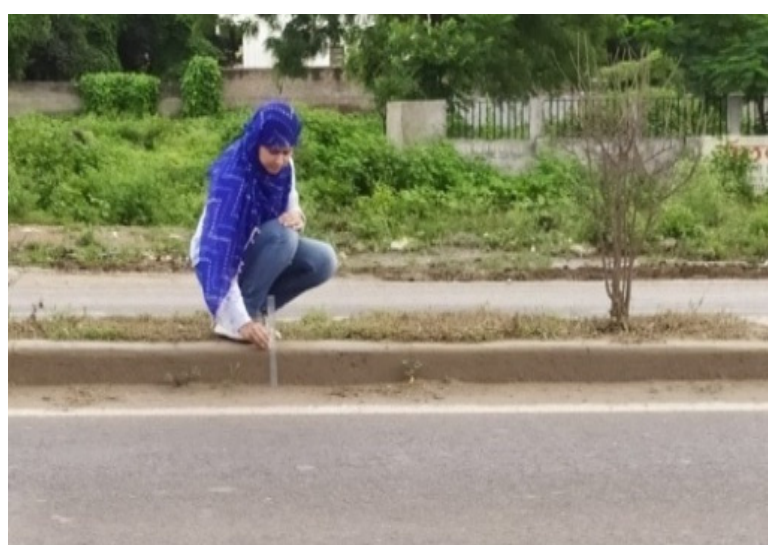

Fig.10 Insufficient Median Height

\subsection{Major hindrances on Beed bypass road}

1. Accidents occur on this road frequently.

2. Heavy traffic on road

3. People often drive from wrong side of road.

4. Drink and drive cases are seen more on this road.

5. Speed limit is frequently violated by drivers.

6. Rickshaw drivers and motorcyclists drive carelessly and try to overtake heavy vehicles without caution.

7. Road users do not follow signals properly.

8. There are obstructions to vision at intersections.

9. Unauthorized breaking of median at number of places.
10. Road markings are hidden behind trees and advertisement boards.

11. After closure of railway gate near Deolai chowk all traffic from Shivaji nagar road come on bypass road which makes the movement of fast-moving traffic difficult and dangerous.

12.People don't follow rules even if traffic police is available on the junction.

13. Road width is insufficient according to current traffic requirement.

14. The slope of the shoulder is not properly levelled at many places this leads to formation of cuts at the edges.

15.Absence of pedestrian markings.

\subsection{Traffic volume study}

Along the length of Bypass road, two black spots were identified as MIT chowk and Deolai chowk where maximum accidents were recorded in past. It was decided to perform traffic survey on these junctions. On $16^{\text {th }}$ February and $31^{\text {st }}$ August 2019, survey conducted on MIT chowk. On 14 ${ }^{\text {th }}$ March and $7^{\text {th }}$ October 2019 conducted the survey on Deolai chowk. Manual readings were taken regarding counting number of vehicles crossing the roads. Vehicles were categorised as Heavy duty vehicles, Bus/ truck, passenger cars, Auto rickshaws and two wheelers. Vehicles type has direct impact on overall results and interpretation of data.

\subsection{Factors affecting Traffic counting}

Factors affecting traffic counting are as follows:

1. Weather conditions like rain, fog, storms, etc $[8,9]$.

2. Traffic composition includes assessing which category of vehicles are more in number.

3.Purpose of the traffic counting.

4. Method for vehicle counting which may be manual or automated counting machine

5.Location of the study which was already finalised as black spots which recorded maximum accidents.

6.Direction of flow which may be one way or dual [10].

7.Width of road lane meeting the junction.

8 . Road type may be bituminous or concrete

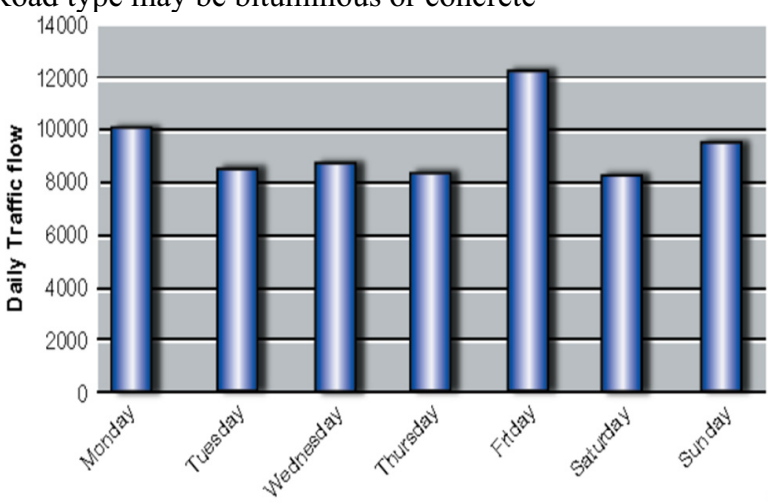

Days of the week

Fig. 11 Daily traffic flow Beed bypass road. 
Daily traffic flow on Beed bypass road is represented as bar chart as shown in fig. 11 in passenger car unit (PCU).

\subsection{Identification of blackspots}

After the study of accident data, traffic volume study and site observations as given above MIT chowk and Deolai chowk are identified as blackspots.

\subsubsection{MIT chowk}

MIT chowk is near an institutional area so there is presence of large number of students in day time. Also, at the junction, there is falling gradient which eventually make the vehicle reach the junction at high speed. Sufficient Set back distance (SBD) is not available while taking right turn from MIT college. All these factors lead to accidents. Fig.12 shows photograph of MIT chowk taken on investigation day.

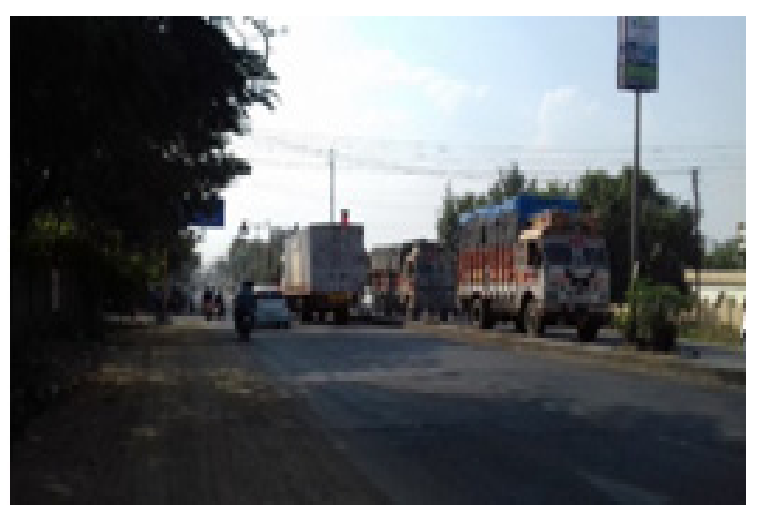

Fig. 12 MIT chowk

\subsubsection{Deolai chowk}

Deolai chowk is one of the most crowded junctions in the Aurangabad city. Many accidents had occurred at this chowk. Small vehicles like two wheelers were involved in accidents. The road going towards Shivaji Nagar has a railway crossing and whenever this road is closed for the crossing of train then the traffic on this road gets diverted to the Deolai chowk making it more difficult for regular traffic at the chowk. Fig. 13 shows photograph of Deolai chowk taken on investigation day.

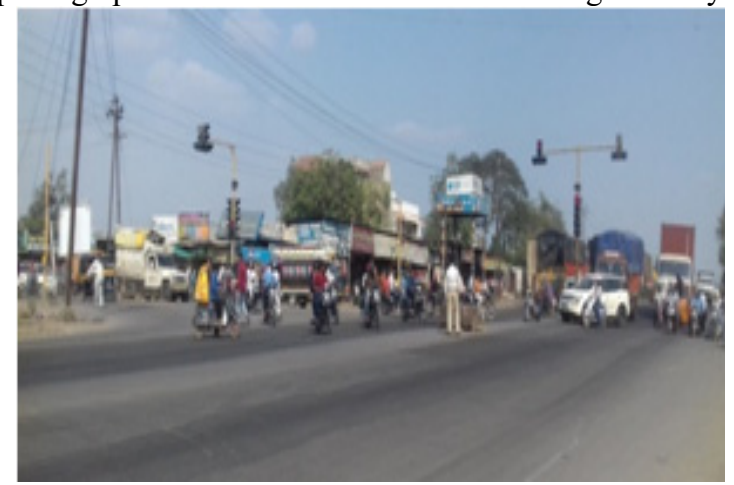

Fig.13 Deolai Chowk

\section{Recommandations}

\subsection{Observations recorded}

The road survey was done from Mahanubhav Ashram (T- point of Paithan road) to Zalta Phata. Following observations were made on investigation day.

1. Each and every corner of the road was surveyed.

2. Foot paths were checked.

3. Sign boards and their location were checked.

4. Pot holes where checked.

5. Lane marking was checked.

6. Position of speed breakers were checked and also their conditions.

7. People and vehicles travelling wrong side were photographed.

8. The total length of the road surveyed was $13.1 \mathrm{~km}$.

9. Almost footpaths were damaged and broken or at some places they were occupied by small shops.

10. Some sign boards were tilted, some were missing.

11. Total 39 pot holes were present

12. Lane marking was missing at some of the roads, at some places they were not at the center.

13. Almost all speed breakers have to be constructed properly.

14. More than $30 \%$ of the people as well as the vehicles were travelling wrong side.

\subsection{Recommendations}

Based upon observations made on investigation day and thereafter by studying the photographs are readings of vehicle counting following recommendations were made to improve the quality of road in order to avoid further accidents.

\subsubsection{Immediate measures}

1. Provide the speed breaker at MIT \& Deolai chowk.

2. Hazard marker to be provided wherever they are missing.

3. Shrubs in shoulders to be removed. Shoulders to be dressed to proper slope.

4. Repairs of railing on culverts to be carried out.

5. Pavement marking is to be provided.

6. Median gap is to be closed.

7. Drainage needs to be improved.

8. Fallen shoulders to be restored.

9. Speed breaker shall be extended to full width of the pavement and shall be marked.

10. No. of electric poles close to the road need to be shifted. Shall be provided with hazard marking to highlight their position to the drivers.

11. Provide pedestrian way.

12. Provide street light at MIT junction.

13. Green time should be extended up to $45-50$ seconds at MIT chowk of road Paithan to Zalta Phata $\&$ vice versa during 11 am to $5 \mathrm{pm}$. 
14. Plantation at the junctions should be removed so that approaching vehicle can see the clear view of traffic.

15. Branches of trees projecting over the road at a height less than $7 \mathrm{~m}$ should be removed.

16. Pot holes and ruts should be repaired.

17. Traffic rules should be strictly followed.

\subsubsection{Long term measures at Deolai chowk}

Provide flyover on the given direction as shown by green arrow in fig. 14. It will have following advantages.

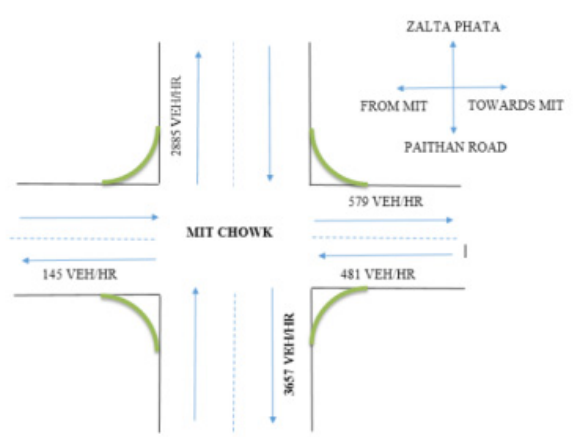

Fig. 14 Position of recommended flyover at MIT chowk.

\section{Conclusion}

Current research study regarding road safety audit highlighted issues in safety management. It examines the defects in the road safety in relation to vehicular traffic. It suggested the various recommendations which are easy to do and are economical. The audit is applied to the risks outside the framework of standards and codes.

The accident data, traffic volume and field observations showed risk involved while travelling on the road. Also, it gives the information about causes of accidents and vulnerable road users. Following observations where made while assessing traffic survey and accident data of Beed Bypass road, particularly at two junctions in Aurangabad city.

1. MIT chowk and Deolai chowk are identified as black spots.

2. It is observed that negligent driving, rules violation, over speeding of heavy vehicles and avoiding safety gears like seat belts and helmets are the prominent reasons for the accidents.

3. Further recommendations made at both accident spots must be adapted immediately to avoid further accidents. These recommendations may be subjected to revisions and alternations, but the immediate action will avoid further deaths and injuries.

\section{References}

1. A.S. Bagi, D.N. Kumar, IOSR Journal of Mechanical and Civil Engineering, 1, 6, pp. 1-8, (2012).

2. IRC:SP:84-2014, Indian Road Congress, (2014)

3. IRC:SP:88-2010, Indian Road Congress, (2010).

4. K. Meshram and H.S. Goliya, International Journal of Application or Innovation in Engineering \& Management, 2, 7, (2013).

5. A. Theofilatos and G.Yannis, Accident Analysis and Prevention, 72, pp. 24465, (2014).

6. A.B. Labana, V.A. Parikh, V.P. Parekh, International Journal of Advance Engineering and Research Development, 2, 5, (2015).

7. O. Gholap, N. Shinde, V. Shelke, N. Navale, and K. Deshmukh, International Journal of Engineering Research \& Technology, 7, 4, (2018).

8. A. H. Ghods, F. Saccomanno and G. P. Guido, Procedia in Social and Behavioral sciences,53, pp. 834-841, (2012).

9. M. Williamson and H. Zhou, Procedia - Social and Behavioral Sciences, 43, pp. 330-338, (2012).

10. R.R. Dinu, A. Veeraragavan, Journal of safety Research, 42, pp.39-42, (2011). 